\title{
A Comparative Evaluation of Canal Transportation and Centering Ability of Three Different Ni-Ti File Systems - An In Vitro CBCT Study
}

\author{
Panithini DB*, Sita Rama Kumar M, Girija. S. Sajjan, Madhu Varma K, Kalyan Satish R, Madhavi K \\ Department of Conservative Dentistry and Endodontics, Vishnu Dental College and Hospital, Bhimavaram, Andhra Pradesh, India
}

Received May 31, 2021; Revised July 3, 2021; Accepted July 25, 2021

\section{Cite This Paper in the following Citation Styles}

(a): [1] Panithini DB, Sita Rama Kumar M, Girija. S. Sajjan, Madhu Varma K, Kalyan Satish R, Madhavi K, "A Comparative Evaluation of Canal Transportation and Centering Ability of Three Different Ni-Ti File Systems - An In Vitro CBCT Study," Open Journal of Dentistry and Oral Medicine, Vol. 9, No. 1, pp. 7 - 13, 2021. DOI: 10.13189/ojdom.2021.090102.

(b): Panithini DB, Sita Rama Kumar M, Girija. S. Sajjan, Madhu Varma K, Kalyan Satish R, Madhavi K (2021). A Comparative Evaluation of Canal Transportation and Centering Ability of Three Different Ni-Ti File Systems - An In Vitro CBCT Study. Open Journal of Dentistry and Oral Medicine, 9(1), 7 - 13. DOI: 10.13189/ojdom.2021.090102.

Copyright $(2021$ by authors, all rights reserved. Authors agree that this article remains permanently open access under the terms of the Creative Commons Attribution License 4.0 International License

\begin{abstract}
Successful root canal therapy depends on many factors. One of the most important steps in any root canal treatment is biomechanical preparation. Additionally, respecting the original shape of the canal is of the same importance. Otherwise, canal aberrations such as transportation will be created. Purpose: To evaluate the canal transportation and canal centering ability of ProTaper Next (PTN), TruNatomy (TN), and Neohybrid (NH) file systems using cone-beam computed tomography. Materials and methods: Thirty extracted single-rooted mandibular premolars were decoronated and divided into three experimental groups, with ten in each group. Group I - ProTaper Next (PTN), Group II - TruNatomy (TN), and Group III - Neohybrid (NH) file systems. Cone-beam computed tomographic pre-scan were taken, followed by biomechanical preparation with the respective file systems. Post CBCT scans were taken and compared with pre-scans for canal transportation and canal centering ability at the levels of 3, 6, and $9 \mathrm{~mm}$. The data obtained were statistically analyzed. Results: Using One way ANOVA and Post hoc analysis, canal transportation at the level of $6 \mathrm{~mm}$ from the apex, group II and group III have shown statistical significance compared to group I, and no statistically significant differences were seen at the levels of $3 \mathrm{~mm}$ and $9 \mathrm{~mm}$. There is no statistically significant difference in canal centering ability among the three groups at the levels of 3,6, and $9 \mathrm{~mm}$ from the apex. Conclusion: Under the in vitro conditions of the study, ProTaper Next
\end{abstract}

(PTN), Trunatomy (TN), and Neohybrid (NH) rotary systems have shown similar behavior concerning canal transportation and canal centering ability.

Keywords ProTaper Next (PTN), TruNatomy, Neohybrid, Cone-Beam Computed Tomography (CBCT), Canal Transportation, Canal Centering Ability

\section{Introduction}

The success of root canal treatment varies on effective cleaning and shaping of the root canal system without deviating from the original anatomy [1]. Irrespective of the instrumentation technique, cleaning and shaping procedures invariably lead to dentin removal from the canal walls [2]. Canal Transportation is defined as removing the canal wall structure on the outer curve in the apical half of the canal because of the likelihood of the files to restore themselves to their original linear shape during canal preparation [3]. The shaping ability of a particular file system is evaluated by analyzing postoperative root canal conicity, taper, the flow of the prepared root canal, and maintenance of the original canal shape. The capability of an instrument or a technique to allow the prepared canal to stay centered is seen as a positive aspect, whereas the canal transportation and preparation errors were seen as a negative aspect. Various 
undesirable apical preparation outcomes, such as damage to the apical foramen, elbow formation, zip formation, and perforation, have been described as possible results of canal transportation [4]. Ni-Ti rotary instrumentation has made endodontics easier and faster than manual instrumentation, resulting in reliable and predictable root canal shaping. Because of the $\mathrm{Ni}-\mathrm{Ti}$ alloy's unique properties, these instruments can improve both the morphological characteristics and safety of canal shaping [5]. The ProTaper Next (PTN) (Dentsply Sirona Endodontics, Ballaigues, Switzerland) is an innovative Ni-Ti file system made from M-Wire technology. It has a rectangular cross-section with an offset mass of rotation with a variable taper. Its off-centered design gives the file snake-like "swaggering effects" that decrease the screw effect and the dangerous taper lock minimizing the contact between a file and dentin [6]. Dental TruNatomy (TN) and Neohybrid (NH) file systems made up of special Ni-Ti alloys subjected to various thermal treatment processes are introduced recently. TruNatomy (TN) (Dentsply Sirona, Ballaigues, Switzerland) file system characterized by different geometries and sizes of the instruments, memory, and specific metallurgical treatment. It is designed from a $0.8 \mathrm{~mm} \mathrm{Ni}$-Ti wire heated by a special treatment, resulting in super-elastic properties and less memory. It has been claimed to provide slim shaping instrumentation because of its geometry, regressive tapers, and slim design [7,8]. Neohybrid (NH) (Orikam Healthcare India Private Limited) files are made of CTA (controlled thermal activation) wire with an off-centered rectangular cross-section that improves flexibility, and its swaggering movement minimizes the engagement between the file and canal dentin, effectively reducing the taper lock and screw-in forces inside the canal [9]. A noninvasive Cone-beam computed tomography (CBCT) evaluates the canal anatomy and compares the canal shape before and after preparation. Using cone-beam computed tomography (CBCT), proper cross-sections of roots are provided, and 3-dimensional $\mathrm{CT}$ images are reconstructed simultaneously with more precision than other routine techniques [10]. TruNatomy (TN) and Neohybrid (NH) to enhance their efficiency in terms of apical transportation and centering ability was not addressed much. Considered the factors mentioned above, the study aimed to evaluate and compare the canal transportation and centering ability after instrumentation with ProTaper Next (PTN), TruNatomy (TN), and Neohybrid (NH) Ni-Ti rotary file systems using CBCT.

\section{Materials and Methods}

\subsection{Selection and Specimen Preparation}

A total of thirty freshly extracted human single-rooted mandibular premolar teeth for an orthodontic treatment purpose were gathered for this study. The sample size calculation is based on a previous study using $G$ power software at $80 \%$ confidence and a p-value set at less than 0.05 [1]. Teeth with any previous endodontic treatment, fractures, pathological root resorptions, calcifications, and immature teeth were excluded from the study. Confirmation of the presence of a single root and canal in each tooth was done on radiovisiography. All the samples were standardized to a length of $16 \mathrm{~mm}$ by de coronation using a double-faced diamond disc (KG Sorensen, Barueri, SP, Brazil). The root canal length was measured by the penetration of a size $10 \mathrm{~K}$-file (Mani, Japan) until it touched the apical foramen and then subtracting $0.5 \mathrm{~mm}$. Teeth were arbitrarily divided into three groups $(n=10)$ and were embedded in the putty blocks to obtain a constant position.

\subsection{Initial Scanning}

The template is horizontally fitted to chin support with its occlusal plane parallel to the plate. A pre CBCT scan is done for all teeth before instrumentation. The exposure period was $3.0 \mathrm{~s}$, operating at $75 \mathrm{kV}$ and $2.0 \mathrm{~mA}$, and the images are accumulated in the computer's hard disk for further comparison between pre- and post-instrumentation data using DICOM software.

\subsection{Final Root Canal Preparation}

After initial scans, root canals were instrumented as follows: Group 1: Canals were shaped using ProTaper Next (PTN) (Dentsply Sirona Endodontics, Ballaigues, Switzerland) rotary files. ProTaper Next SX file is used as an orifice modifier followed by a shaping file X1 of size 17/0.04 and X2 of size 25/0.06 was used till the working length with EConnect $\mathrm{S}$ (Eighteeth, China) Endo motor. Recapitulation was done after every instrumentation with a $10 \mathrm{~K}$-file, and irrigation was done. Group 2: Canals were shaped using TruNatomy (TN) (Dentsply Sirona, Ballaigues, Switzerland) rotary files. The TruNatomy Orifice Modifier and a glide path file of tip size 17/0.04 were used initially, followed by the TruNatomy Prime shaping file of tip size 25/0.04 for apical preparation using EConnect S (Eighteeth, China) Endo motor. Recapitulation and irrigation were done similar to Group I. Group 3: Canals were shaped using Neohybrid (NH) (Orikam Healthcare India Private Limited) rotary files. The Orifice opener and a glide path file of tip size 17/0.04 were used initially, followed by a shaping file of tip size 25/0.04 till the working length with EConnect $\mathrm{S}$ (Eighteeth, China) Endo motor. Recapitulation and irrigation were done similarly to Group I. All the instruments and techniques of usage were according to the manufacturer's instructions. Biomechanical preparation was done using the respective files, and irrigation was done using 3\% sodium hypochlorite solution $(\mathrm{NaOCl})$ (Parcan, Septodont Healthcare PVT LTD., India), 17\% 
ethylenediaminetetraacetic acid (EDTA) (Dent Wash, Prime Dental PVT LTD., India) and 0.9\% normal saline (NS).

\subsection{Final Scanning and Evaluations}

The teeth were again prepared for postoperative CBCT scanning using the same parameters, and the pre instrumentation data stored are compared with post-instrumentation data using CBCT software (Kodak 9000 DICOM Software CS 9000 3D) [1]. Three axial tomograms were selected for each specimen. The first one corresponding to the area located $3 \mathrm{~mm}$ (apical third), the second one at $6 \mathrm{~mm}$ (middle third), and the third one at 9 $\mathrm{mm}$ (cervical third) from the root apex.

\subsection{Evaluation of Canal Transportation}

Determination of the amount of canal transportation was by calculating the shortest distance from the edge of the pre instrumented canal to the edge of the root's outer surface on mesial and distal aspects and then comparing this with the same measurements obtained from the instrumented images [11] [Fig. 2-4]. Using the formula introduced by Gambill et al. [12], transportation was calculated by $(\mathrm{A} 1-\mathrm{A} 2)-(\mathrm{B} 1-\mathrm{B} 2)$, where $\mathrm{A} 1$ is the shortest distance from the edge of the outer surface of the root to the edge of the inner surface of the uninstrumented canal on the mesial aspect, B1 is the shortest distance from the edge of the outer surface of the root to the edge of the inner surface of the uninstrumented canal on the distal aspect, A2 is the shortest distance from the edge of the outer surface of the root to the edge of the instrumented canal on the mesial aspect, and B2 is the shortest distance from the edge of the outer surface of the root to the edge of the inner surface of the canal after instrumentation on the distal aspect [Fig. 1]. According to the formula given above, a result other than 0 indicates that transportation has occurred in the canal. [12]

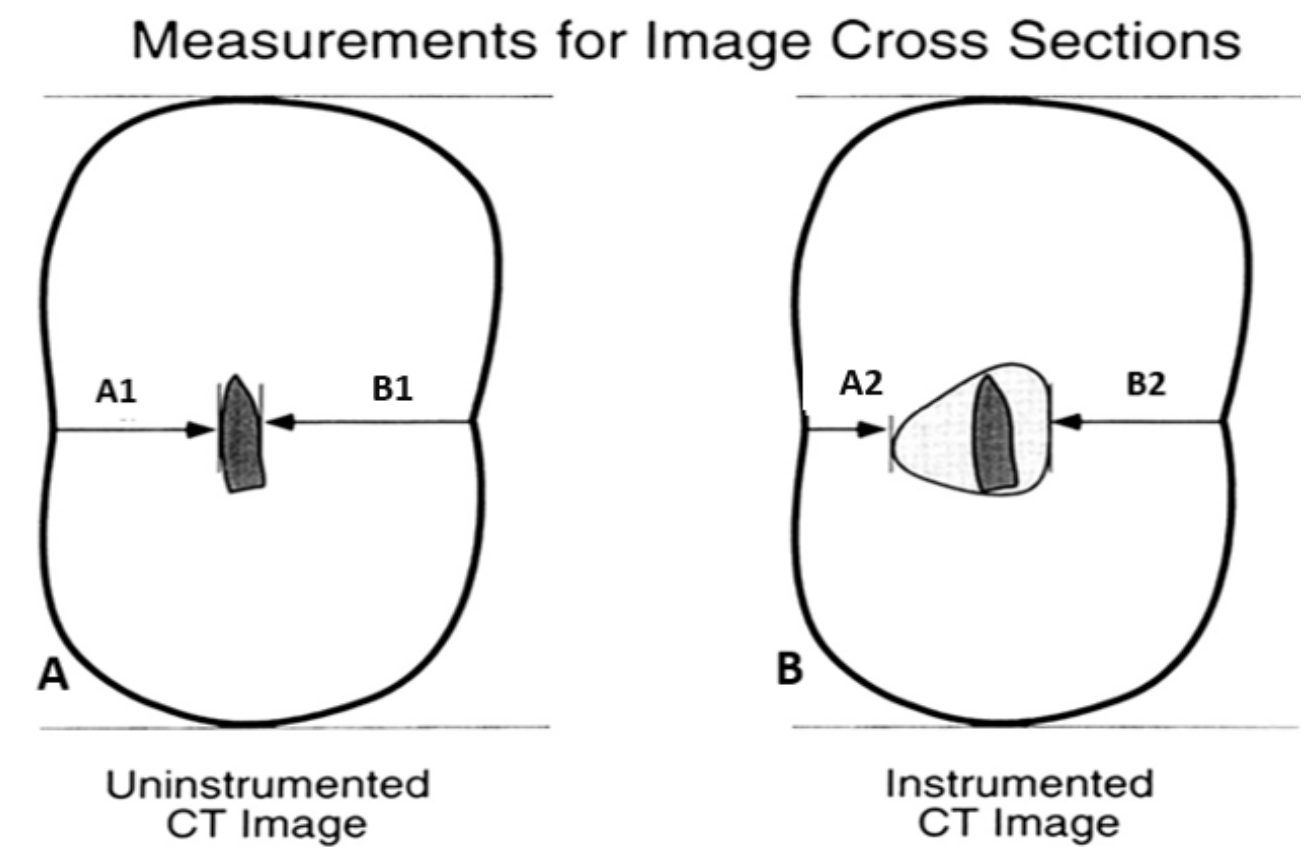

Figure 1. Schematic diagram of axial tooth sections showing how transportation and centering ratios were derived. A) Uninstrumented image B) Instrumented image (by Gambill, 1996) 

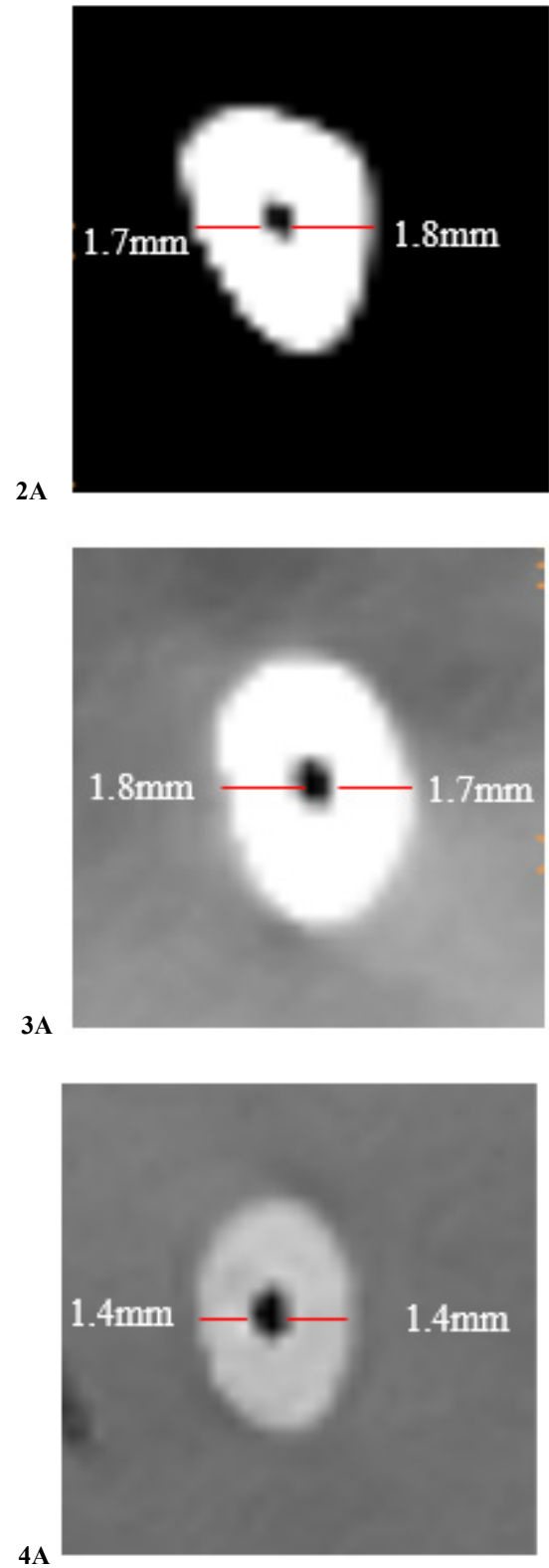
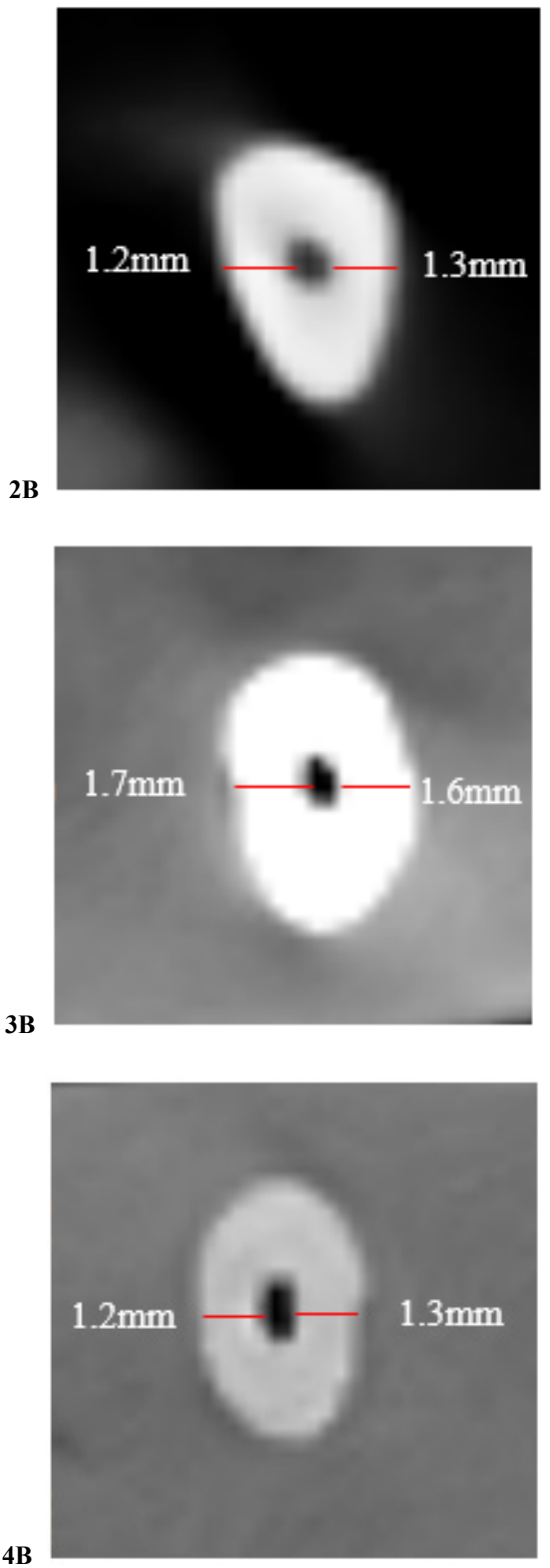

Figure 2-4. (A) Showing pre-instrumentation images (B) Showing post-instrumentation images of 2. ProTaper Next (PTN), 3. TruNatomy (TN), and 4. Neohybrid $(\mathrm{NH})$ at the region of $9 \mathrm{~mm}$ from the apex.

\subsection{Evaluation of Canal Centering Ability}

It is calculated by using the following ratio: (A1 $\mathrm{A} 2) /(\mathrm{B} 1-\mathrm{B} 2)$ or $(\mathrm{B} 1-\mathrm{B} 2) /(\mathrm{A} 1-\mathrm{A} 2)$. If the numbers are not equal, the lower figure was considered the numerator of the ratio. According to this formula, a result of 1 indicates perfect centering [12].

\subsection{Statistical Analysis}

The data extracted were tabulated and subjected to statistical analysis using the statistical package for the social sciences IBM SPSS Statistics version 22.0 software and One-way Analysis of Variance test for intragroup comparison and Tukey's post hoc test for intergroup examination.

\section{Results}

\subsection{Canal Transportation}

Canal Transportation At the level of $3 \mathrm{~mm}$, there was no statistically significant difference in canal transportation among the groups. However, at the level of $6 \mathrm{~mm}$, group II and III have shown less transportation compared with group I. Hence a statistically significant difference is seen in group II and group III $(\mathrm{P}<.05)$ when compared with group I, Whereas no significant difference is seen among group II and group III. At the level of $9 \mathrm{~mm}$, there was no 
significant difference in canal transportation among the groups. [Table 1,3]

\subsection{Canal Centering Ability}

Table 1. Canal transportation after biomechanical preparation using ANOVA

\begin{tabular}{|c|c|c|c|c|}
\hline Levels & Groups & Mean & Std. dev & P-value \\
\hline \multirow{3}{*}{$3 \mathrm{~mm}$} & Group I & 0.01 & 0.21 & \multirow{3}{*}{0.986} \\
\hline & Group II & 0.02 & 0.12 & \\
\hline & Group III & 0.02 & 0.09 & \\
\hline \multirow{3}{*}{$6 \mathrm{~mm}$} & Group I & -0.13 & 0.14 & \multirow{3}{*}{0.006} \\
\hline & Group II & 0.05 & 0.05 & \\
\hline & Group III & 0.05 & 0.17 & \\
\hline \multirow{3}{*}{$9 \mathrm{~mm}$} & Group I & -0.05 & 0.08 & \multirow{3}{*}{0.580} \\
\hline & Group II & -0.05 & 0.05 & \\
\hline & Group III & -0.01 & 0.13 & \\
\hline
\end{tabular}

At $3 \mathrm{~mm}$ from the apex, group I maintained a better centering ability than group II and group III with a mean value of 0.76 , followed by group III with a mean value of 0.74 and group II with a mean value 0.56 . At $6 \mathrm{~mm}$ from the apex, group II maintained a better centering ability than group I and group III with a mean value of 0.75 , followed by the group I with a mean value of 0.71 and group III with a mean value 0.59 . At $9 \mathrm{~mm}$ from the apex, group II maintained a better centering ability than group I and group III with a mean value of 0.76 , followed by the group I with a mean value of 0.73 and group III with a mean value 0.68 . As analyzed by the One-way Analysis of Variance test and Tukey's post hoc test, there is no statistically significant difference in canal centering ability among the groups at the levels of 3,6 and $9 \mathrm{~mm}$ from the apex. [Table 2,4]

Table 2. Canal centering ability after biomechanical preparation using ANOVA

\begin{tabular}{|c|c|c|c|c|}
\hline Levels & Groups & Mean & Std. dev & P-value \\
\hline \multirow{3}{*}{$3 \mathrm{~mm}$} & Group I & 0.73 & 0.27 & \multirow{2}{*}{0.26} \\
\cline { 2 - 4 } & Group II & 0.56 & 0.24 & \\
\cline { 2 - 4 } & Group III & 0.74 & 0.28 & \\
\hline \multirow{3}{*}{$6 \mathrm{~mm}$} & Group I & 0.71 & 0.32 & \multirow{2}{*}{0.48} \\
\cline { 2 - 4 } & Group II & 0.75 & 0.26 & \\
\cline { 2 - 4 } & Group III & 0.59 & 0.31 & \multirow{2}{*}{0.79} \\
\hline \multirow{3}{*}{$9 \mathrm{~mm}$} & Group I & 0.73 & 0.23 & \multirow{2}{*}{0.25} \\
\cline { 2 - 4 } & Group II & 0.76 & 0.30 & \multirow{2}{*}{} \\
\cline { 2 - 4 } & Group III & 0.68 & \multicolumn{2}{|c}{} \\
\hline
\end{tabular}

Table 3. Canal transportation after biomechanical preparation using post hoc analysis

\begin{tabular}{|c|c|c|c|c|c|}
\hline levels & Group & Groups & Mean difference & Std. Error & Significance \\
\hline \multirow{3}{*}{$3 \mathrm{~mm}$} & \multirow{2}{*}{ Group I } & Group II & -0.010 & 0.067 & 0.988 \\
\hline & & Group III & -0.010 & 0.067 & 0.988 \\
\hline & Group II & Group III & 0.000 & 0.067 & 1.000 \\
\hline \multirow{3}{*}{$6 \mathrm{~mm}$} & \multirow{2}{*}{ Group I } & Group II & -0.180 & 0.059 & 0.014 \\
\hline & & Group III & -0.180 & 0.059 & 0.014 \\
\hline & Group II & Group III & 0.000 & 0.059 & 1.000 \\
\hline \multirow{3}{*}{$9 \mathrm{~mm}$} & \multirow{2}{*}{ Group I } & Group II & 0.000 & 0.043 & 1.000 \\
\hline & & Group III & -0.040 & 0.043 & 0.637 \\
\hline & Group II & Group III & -0.040 & 0.043 & 0.637 \\
\hline
\end{tabular}

*The mean difference is significant at the level of 0.05 .

Table 4. Canal centering ability after biomechanical preparation using post hoc analysis

\begin{tabular}{|c|c|c|c|c|c|}
\hline levels & Group & Groups & Mean difference & Std. Error & Significance \\
\hline \multirow{3}{*}{$3 \mathrm{~mm}$} & \multirow{3}{*}{ Group I } & Group II & 0.170 & 0.120 & 0.351 \\
\cline { 2 - 6 } & & Group III & -0.010 & 0.120 & 0.996 \\
\cline { 2 - 6 } & Group II & Group III & -0.180 & 0.120 & 0.311 \\
\hline \multirow{3}{*}{$6 \mathrm{~mm}$} & \multirow{3}{*}{ Group I } & Group II & -0.040 & 0.135 & 0.753 \\
\cline { 2 - 6 } & \multirow{3}{*}{ Group II } & Group III & 0.120 & 0.135 & 0.654 \\
\hline \multirow{3}{*}{$9 \mathrm{~mm}$} & \multirow{2}{*}{ Group I } & Group III & 0.160 & 0.135 & 0.775 \\
\cline { 2 - 6 } & \multirow{2}{*}{ Group II } & Group II & -0.030 & 0.119 & 0.966 \\
\cline { 2 - 6 } & & Group III & 0.050 & 0.119 & 0.908 \\
\hline
\end{tabular}

*The mean difference is significant at the level of 0.05 . 


\section{Discussion}

An ideal prepared root canal should have a progressively tapering conical shape that preserves the apical foramen and the original canal shape [5]. Irrespective of the instrumentation technique, cleaning and shaping procedures invariably lead to dentin removal from the canal walls. Excessive removal of dentin in a single direction within the canal rather than in all directions equidistantly from the main tooth axis causes deviation of the canal [13]. Many studies reported that canal transportation was less with $\mathrm{Ni}-\mathrm{Ti}$ files when compared to the traditional stainless steel files [14]. It may be attributed to the increased flexibility and torsional resistance of $\mathrm{Ni}-\mathrm{Ti}$ files compared to the stainless steel files. The superelasticity of NiTi instruments permits bringing about a constant tapered root canal. The advantages of NiTi instruments in root canal preparation are well documented. However, their cutting ability is a complex interrelationship of multiple parameters such as the cross-sectional design, helical and rake angles, metallurgical properties, and surface treatments of the instrument [15]. These design features influence the flexibility, cutting efficiency, canal transportation, centering ability, and safety of instruments. In this study, CBCT is used to evaluate canal transportation and centering ability. There are several methodologies to evaluate different instrumentation techniques in preparing root canals. But one of the latest innovations in the medical field is CBCT for study purposes, and this scientific tool could develop potential in endodontic research. Moreover, this study shows that the quality of the three-dimensional images obtained by CBCT scanning is an accurate and efficient method of assessing root canal instrumentation $[2,16,17]$. The present study evaluated three rotary $\mathrm{Ni}-\mathrm{Ti}$ file systems for their shaping ability, namely, ProTaper Next (PTN), TruNatomy (TN), and Neohybrid (NH). A study done by Hasheminia et al.[18] revealed that the use of $6 \%$ tapered instruments resulted in less canal transportation than the use of the $8 \%$ tapered. This finding can be attributed to the difference in instrument taper that may affect canal transportation. The present study shows, at the level of $6 \mathrm{~mm}$ TruNatomy (TN) and Neohybrid (NH) files of $4 \%$ taper recorded significantly less transportation when compared with ProTaper Next (PTN) file system of $6 \%$ taper. TruNatomy (TN) file system has shown a significant difference in minimal transportation compared to ProTaper Next (PTN) file system, and it had stated that TruNatomy (TN) instruments safeguard the structural dentin and tooth integrity due to their instrument geometry, regressive tapers, and slim design, along with the heat treatment of the NiTi alloy [19]. Neohybrid (NH) has also shown less transportation comparative to ProTaper Next (PTN) with a significant difference at $6 \mathrm{~mm}$ from the apex as we have limited the instrumentation to a size of $4 \%$ taper, and its swaggering movement minimizes the engagement between the file and canal dentin, effectively reducing the taper lock and screw-in forces inside the canal [9]. At the $3 \mathrm{~mm}$ and $9 \mathrm{~mm}$ levels, no significant difference was seen among the three file systems. Considering the direction of canal transportation, ProTaper Next (PTN) has shown distal transportation whereas, TruNatomy (TN) and Neohybrid (NH) have shown mesial transportation. This was similar to the study done by Mamede-Neto et al.[20], ProTaper Next showed the distal transportation compared with Mtwo, Wave one, and BioRace, which showed mesial transportation. None of the instruments tested in the present study remained perfectly centralized within the root canal concerning canal centering ability. Kabil et al. [21] found no significant difference in the centering ability of ProTaper Next (PTN) and TruNatomy (TN) file systems. Similar findings are shown with no statistically significant difference among the groups at the levels of 3 , 6 , and $9 \mathrm{~mm}$ from the apex, attributing to the similar shaping ability of the file systems.

\section{Conclusion}

Under the in vitro conditions of the study, ProTaper Next (PTN), Trunatomy (TN), and Neohybrid (NH) rotary systems have shown similar behavior concerning canal transportation and canal centering ability.

\section{Conflicts of Interest}

Authors declared no conflicts of interest.

\section{Financial Support}

None

\section{REFERENCES}

[1] Jain A, Asrani H, Singhal AC, Bhatia TK, Sharma V, Jaiswal P. Comparative evaluation of canal transportation, centering ability, and remaining dentin thickness between WaveOne and ProTaper rotary by using cone-beam computed tomography: An in vitro study. Journal of conservative dentistry: JCD. Vol. 5, no. 19, pp. 440-444, 2016, DOI: 10.4103/0972-0707.190024.

[2] Rao MR, Shameem A, Nair R, Ghanta S, Thankachan RP, Issac JK. Comparison of the remaining dentin thickness in the root after hand and four rotary instrumentation techniques: An in vitro study. The journal of contemporary dental practice. vol. 4 , no. 14 , pp. $712-717,2013$, DOI: 10.5005/jp-journals-10024-1389.

[3] Dhingra A, Ruhal N, Miglani A. Evaluation of single-file 
systems Reciproc, One shape, and WaveOne using cone-beam computed tomography-an in vitro study. Journal of clinical and diagnostic research: JCDR. Vol. 4 no. 9, pp. ZC30-ZC34, 2015, DOI: $10.7860 / \mathrm{JCDR} / 2015 / 12112.5803$.

[4] Schäfer E, Dammaschke T. Development and sequelae of canal transportation. Endodontic Topics. vol. 1, no. 15, pp. 75-90, 2006.

[5] Chaudhary NR, Singh DJ, Somani R, Jaidka S. Comparative evaluation of the efficiency of different file systems in terms of remaining dentin thickness using cone-beam computed tomography: An in vitro study. Contemporary clinical dentistry. vol. 3 , no. 9, pp. 367-371, 2018, DOI: 10.4103/CCD.ccd_72_18.

[6] Capar ID, Ertas H, Ok E, Arslan H, Ertas ET. Comparative study of different novel nickel-titanium rotary systems for root canal preparation in severely curved root canals. Journal of Endodontics. Vol. 6, no. 40, pp. 852-856, 2014, DOI: $10.1016 /$ j.joen.2013.10.010.

[7] Peters OA, Arias A, Choi A. Mechanical properties of a novel nickel-titanium root canal instrument: stationary and dynamic tests. Journal of endodontics. vol. 7, no. 46, pp. 994-1001, 2020, DOI: 10.1016/j.joen.2020.03.016.

[8] Dentsply Sirona. TruNatomy Brochure. Available at: https://www.dentsplysirona.com/en/explore/endodontics/tr unatomy.html Accessed Dec 10, 2020.

[9] Orikamhealthcare Neohybrid brochure. Available at https://orikamhealthcare.com/product/neohybrid/ Accessed Dec 25, 2020.

[10] Madani ZS, Haddadi A, Haghanifar S, Bijani A. Cone-beam computed tomography for evaluation of apical transportation in root canals prepared by two rotary systems. Iranian endodontic journal. Vol. 2, no. 9, pp. 109-112, 2014.

[11] Gergi R, Abou Rjeily J, Sader J, Naaman A. Comparison of canal transportation and centering ability of twisted files, Path file-ProTaper system, and stainless-steel hand K-files using computed tomography. Journal of Endodontics. vol. 5 , no. $36, \quad$ pp. 904-907, 2010, DOI: 10.1016/j.joen.2009.12.038

[12] Gambill JM, Alder M, Carlos E. Comparison of nickel-titanium and stainless-steel hand-file instrumentation using computed tomography. Journal of endodontics. vol. 7, no. 22, pp. 369-75, 1996, DOI: $10.1016 / \mathrm{S} 0099-2399(96) 80221-4$.
[13] Hartmann MS, Barletta FB, Fontanella VR, Vanni JR. Canal transportation after root canal instrumentation: a comparative study with computed tomography. Journal of endodontics. Vol. 8, no. 33, pp. 962-965, 2007, DOI: 10.1016/j.joen.2007.03.019.

[14] Garip Y, Günday M. The use of computed tomography when comparing nickel-titanium and stainless steel files during the preparation of simulated curved canals. International Endodontic Journal. Vol. 6, no. 34, pp 452-457, 2001, DOI: 10.1046/j.1365-2591.2001.00416.x.

[15] Hashem AA, Ghoneim AG, Lutfy RA, Foda MY, Omar GA. Geometric analysis of root canals prepared by four rotary NiTi shaping systems. Journal of endodontics. vol. 7, no. 38, pp. 996-1000, 2012, DOI: 10.1016/j.joen.2012.03.018.

[16] Jain A, Gupta AS, Agrawal R. Comparative analysis of canal-centering ratio, apical transportation, and remaining dentin thickness between single-file systems, i.e., OneShape and WaveOne reciprocation: An in vitro study. Journal of conservative dentistry: JCD. vol.6, no. 21, pp. 637-641, 2018, DOI: 10.4103/JCD.JCD_101_18.

[17] Elnaghy AM, Elsaka SE. Evaluation of root canal transportation, centering ratio, and remaining dentin thickness associated with ProTaper Next instruments with and without glide path. Journal of endodontics. vol.12, no. 40, pp. 2053-6, 2014, DOI: 10.1016/j.joen.2014.09.001.

[18] Hasheminia SM, Farhad A, Sheikhi M, Soltani P, Hendi SS, Ahmadi M. Cone-beam computed tomographic analysis of canal transportation and centering ability of single-file systems. Journal of endodontics. vol.12, no. 44, pp. 1788-91, 2018, DOI: 10.1016/j.joen.2018.09.011.

[19] Elnaghy AM, Elsaka SE, Mandorah AO. In vitro comparison of cyclic fatigue resistance of TruNatomy in single and double curvature canals compared with different nickel-titanium rotary instruments. BMC oral health. vol.1, no. 20 , pp. 38 , 2020, DOI: 10.1186/s12903-020-1027-7.

[20] Mamede-Neto I, Borges AH, Guedes OA, de Oliveira D, Pedro FL, Estrela C. Root canal transportation and centering ability of nickel-titanium rotary instruments in mandibular premolars assessed using cone-beam computed tomography. The open dentistry journal. vol.1, no. 11, pp. 71-78, 2017, DOI: 10.2174/1874210601711010071.

[21] Kabil E, Katić M, Anić I, Bago I. Micro-computed Evaluation of Canal Transportation and Centering Ability of 5 Rotary and Reciprocating Systems with Different Metallurgical Properties and Surface Treatments in Curved Root Canals. Journal of Endodontics. vol.3, no. 47, pp. 477-84, 2021, DOI: 10.1016/j.joen.2020.11.003. 